\section{NOVA TELLVS}

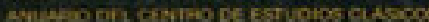

Nova Tellus

ISSN: 0185-3058

novatelu@servidor.unam.mx

Centro de Estudios Clásicos

México

ARAIZA, Jesús

Sobre la amistad según la teoría ética de Aristóteles

Nova Tellus, vol. 23, núm. 2, 2005, pp. 125-159

Centro de Estudios Clásicos

Distrito Federal, México

Disponible en: http://www.redalyc.org/articulo.oa?id=59120933005

- Cómo citar el artículo

- Número completo

- Más información del artículo

- Página de la revista en redalyc.org

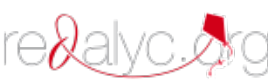

Sistema de Información Científica

Red de Revistas Científicas de América Latina, el Caribe, España y Portugal

Proyecto académico sin fines de lucro, desarrollado bajo la iniciativa de acceso abierto 


\title{
Sobre la amistad según la teoría ética de Aristóteles
}

\author{
Jesús AraizA \\ Universidad Nacional Autónoma de México \\ araimar_jes@yahoo.com.mx
}

RESUMEN: Entre las tesis fundamentales que despliega Aristóteles en el tratado de la amistad $E N$, VIII-IX, deben destacarse ante todo la de la identidad entre la philía y la aretê y su exposición sobre la philautía, como punto culminante dentro de su teoría ética. La amistad de uno con respecto a sí mismo y los sentimientos de amistad que se dan en uno hacia uno mismo - los cuales, a su vez, se dan en un hombre únicamente mediante la adquisición de la virtud-, son causa y fuente de la amistad de uno con respecto a los demás. De donde se sigue que el sentimiento de amistad hacia uno mismo - el cual supone, a su vez, la posesión y actualidad de la virtud ética- es conditio sine qua non de la amistad y afecto hacia nuestros padres, hermanos, seres queridos y hacia el prójimo en general.

$* * *$

ABSTRACT: Among all the fundamental theses in Aristotle's treatise on friendship (EN, VIII-IX), two particularly important ones deserve very careful study: (a) Aristotle's thesis on the identity of philía with aretê and (b) his exposition of philautía, in so far as it is considered to be the climax of all his ethical doctrine. The friendship of a single human being with himself and his affection for himself, which, in Aristotle' view, can be acquired by no other means than purely by ethical virtue, are supposed to be the reason and cause of all friendship and affection towards others. From this it follows, that affection towards oneself - which again presupposes acquisition and practice of ethical virtue - is a conditio sine qua non of friendship and affection towards parents, brothers, kin and, in a more general sense, neighbours and fellow-citizens.

Palabras Clave: amigo, amistad, aristóteles, ética, justicia, philautía, virtud. RECEPCIÓN: 26 de agosto de 2004.

ACEPTACIÓN: 2 de septiembre de 2005. 



\title{
Sobre la amistad según la teoría ética de Aristóteles ${ }^{1}$
}

\author{
Jesús AraizA
}

Son tres las obras de ética aristotélicas que nos han sido transmitidas por la antigüedad: la Ética nicomaquea (EN), la Ética eudemia (EE) y los Magna moralia (MM). Si bien distintas desde el punto de vista cuantitativo y cualitativo, con un desarrollo más extenso y detallado las dos primeras, en las tres éticas se encuentra expuesta substancialmente la misma teoría acerca de la amistad. ${ }^{2}$ En este breve artículo intento destacar los temas fundamentales que aborda Aristóteles en su investigación acerca de la philía — ante todo la amistad en su carácter de virtud o como un modo de ser vinculado a la virtud junto a los rasgos que la caracterizan, la amistad que se da en el hombre excelente, $\sigma \pi \mathrm{ov \delta} \delta \hat{i} о \varsigma$, y la amistad que se da en uno en relación consigo mismo- con el fin de mostrar cómo estos temas se encuentran relacionados entre sí y determinados por el planteamiento y discusión de un tema central —la philautía o el sentimiento de amistad hacia uno mismo - tema en torno al cual parece estar estructurada toda la teoría de la amistad de

\footnotetext{
${ }^{1}$ Esta ponencia fue leída el 17 de Junio de 2004 en Blaubeuren, Alemania, durante el encuentro de becarios convocado por el Intercambio Cultural AlemánLatinoamericano (ICALA), que preside la Prof. Dra. Margit Eckholt, institución gracias a la cual disfruto actualmente de una beca para doctorado en filosofía antigua por la Universidad de Tübingen. Quisiera agradecer aquí también al Dr. Ricardo Salles Afonso de Almeida, por cuya invitación desde hace varios años formo parte de los proyectos PAPIIT IN407705 y CONACYT 40891-H, de los cuales él mismo es responsable.

${ }^{2} E N$, libros VIII-IX; EE, libro VII, y $M M$, II, Cap. 11-17.
} 
Aristóteles en su conjunto. Este artículo, por lo tanto, no es más que un primer acercamiento al estudio de la teoría de la amistad en Aristóteles, y las anotaciones incluidas en él no son más que observaciones preliminares, hechas a partir fundamentalmente de los libros VIII y IX de la Ética Nicomaquea, para una posterior interpretación filosófica y una ulterior comparación de la doctrina expuesta en ésta con respecto a la expuesta en cada una de las otras dos éticas aristotélicas.

Hablar de la amistad, desde la perspectiva de la teoría ética de Aristóteles, supone discurrir en cierto modo acerca de la justicia y, por lo tanto, acerca de toda relación entre cuyas partes se da algo en común. ${ }^{3}$ La justicia es una virtud política por excelencia; es decir, una virtud que se da sobre todo en el seno de la comunidad política, en nuestra relación frente al otro, de modo que, gracias a ella, cada ciudadano obtiene dentro de la comunidad lo que le corresponde. La justicia es, según dice Aristóteles en otro tratado, el orden de la comunidad política y el discernimiento de lo justo. ${ }^{4}$ Pero si la causa del orden en toda comunidad es la justicia, la causa de que una comunidad se mantenga unida es la amistad. ${ }^{5}$ De ahí que los legisladores se afanen más por ella que por la justicia y aspiren sobre todo a

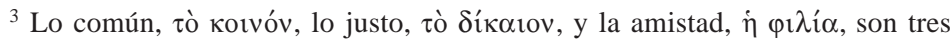
conceptos que aparecen, a lo largo de la investigación aristotélica de la amistad, intrínsecamente unidos. Cfr. EN, VIII, 14, 1161 b 11: "Así pues, toda amistad se

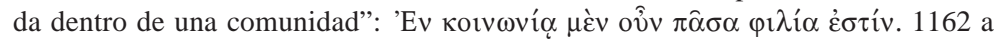
29-31: "Y lo común une. Ahora bien, el investigar cómo conviene que un hombre viva en relación con una mujer y en general un amigo con su amigo, no parece

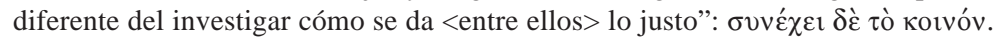

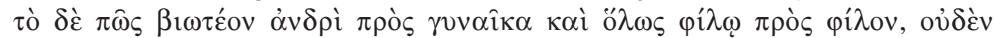

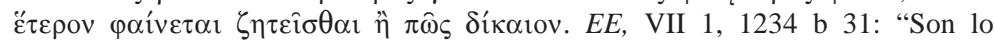
mismo, por consiguiente, o algo próximo la justicia y la amistad": $\tau \alpha$ $\tau$ iòv $\alpha$ $\rho \alpha \hat{\eta}$

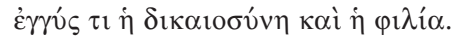

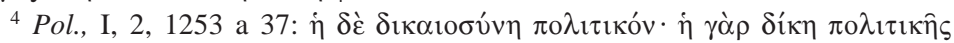

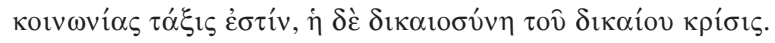

5 EN, VIII, 1, 1155 a 22: "Parece que la amistad mantiene unidas a las ciudades y que los legisladores se esfuerzan más por ella que por la justicia":

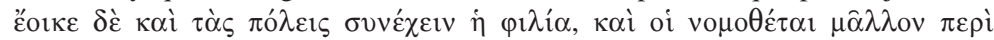

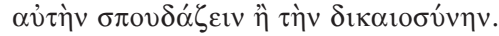


establecer la concordia entre ciudadanos y gobernantes, y a desterrar sobre todo la discordia, que es una especie de enemistad. ${ }^{6}$ Una prueba de que la amistad es una virtud superior y preferible a la justicia, es el hecho de que, cuando los hombres son amigos, no hay entre ellos necesidad de justicia; en cambio, aun siendo justos, precisan ellos de amistad. ${ }^{7}$

Con todo, Aristóteles no excluye que la justicia sea el camino que conduce hacia la amistad. Por el contrario, concede que son los hombres justos los mejor dispuestos hacia ella y afirma que, indagar cómo conviene tratar a un amigo consiste en indagar qué cosa es justa. ${ }^{8}$ Así pues, podemos afirmar, con Aristóteles, que en una comunidad en la que no hay justicia, no puede hablarse tampoco de amistad, de la misma manera como tampoco dos hombres injustos pueden ser amigos entre sí.

Es un hecho por demás evidente que la justicia misma posee dentro de la teoría aristotélica el rango de virtud con las características con que se hace acompañar en general toda virtud ética, ante todo en su calidad de proporción y término

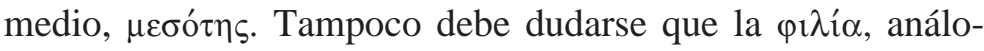
gamente a la justicia, posee el rango de virtud dentro de la teoría de Aristóteles, pues allí reside precisamente la médula del tratado de la amistad en su conjunto y, si esa condición no se admite, no es posible comprender la doctrina aristotélica de la amistad. El hecho de que Aristóteles al inicio del tratado de la amistad en $E N$, VIII, 1 determine que la amistad es una

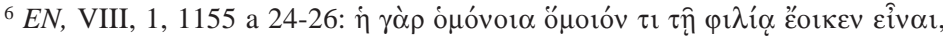

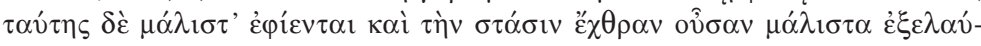
vovoiv.

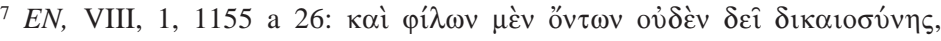

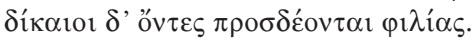

${ }^{8} E N$, VIII, 1, 1155 a 28: "Y el sentimiento de amistad en más alto grado

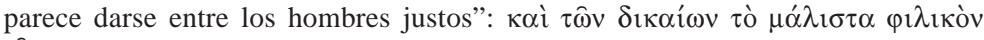

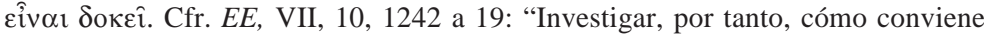
tratar a un amigo es investigar en qué consiste lo justo. Pues en general lo justo

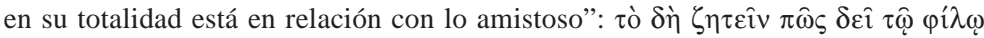

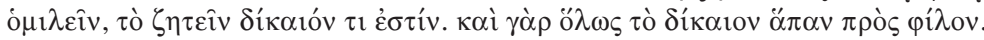




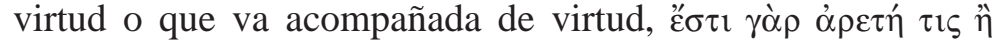
$\mu \varepsilon \tau$ ' $\dot{\alpha} \rho \varepsilon \tau \hat{\jmath} \varsigma$, resulta problemático para algunos intérpretes. En su comentario a la Ética nicomaquea, ${ }^{9}$ Ursula Wolf plantea como problema, si Aristóteles integra en su tratado la amistad como virtud o si la considera más bien como un fenómeno acompañado de virtud. Tomando como punto de partida el

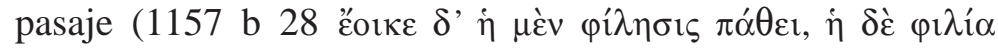

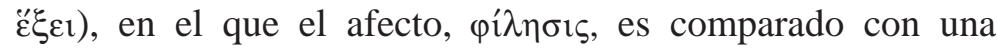

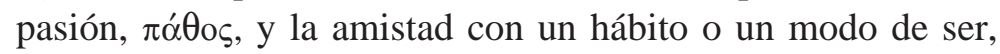
¿ $\xi_{1 \varsigma}$, Wolf supone que Aristóteles se inclina más por la segunda posibilidad, es decir, que considera la amistad no como una virtud, sino como un fenómeno acompañado de virtud. ${ }^{10}$ Sin embargo, a su juicio, la explicación en $E N$ acerca de la amistad como un fenómeno relacionado con la virtud tampoco es suficientemente clara. ${ }^{11}$ En mi opinión, por el contrario, no hay lugar a duda de que, en la fundamentación del tratado de la amistad Aristóteles introduce como primer y principal argu-

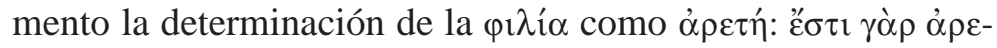
$\tau \eta \dot{~} \tau 1 \zeta\langle\dot{\eta} \varphi \imath \lambda i ́ \alpha\rangle$, y que conviene tomarlo a la letra, y leerlo, según mi interpretación, como sigue: Esta es la primera y principal razón por la cual se debe investigar el tema de la amistad en la esfera de la ética, pues ( $\gamma \alpha$ ó) la amistad es una especie de virtud. Lo que Aristóteles enseguida añade, constituye un segundo argumento o la segunda parte del mismo argumento: $\grave{\eta}_{\mu \varepsilon \tau}$ ' $\alpha \rho \varepsilon \tau \hat{\jmath} \varsigma$. Se debe investigar acerca de la $\varphi \imath \lambda i^{\prime} \alpha$

${ }^{9}$ Cfr. Ursula Wolf, Aristoteles' Nikomachische Ethik, Wiss. Buchges., Darmstadt, 2002, pp. 218-219.

${ }^{10} \mathrm{Ib}$.: "kann man vermuten, dass er die Freundschaft nicht unter die aretai einordnen will, dass seine These vielmehr lautet, sie sei etwas mit einer aretê Verwandtes" (p. 218). "Auch der kurze Hinweis auf die Lehre von der mesotês (1158a10ff.) verstärkt nur den Eindruck, dass die Freundschaft sich nicht als aretê einordnen lässt" (p. 219).

${ }^{11}$ Ib.: "Die einzige klare Beziehung, die Aristoteles zwischen Freundschaft und ethischer aretê herstellt, liegt demnach darin, dass es keine Freundschaft im eigentlichen Sinn gibt, ohne dass die in der Freundschaftsrelation stehenden Personen die ethische aretê besitzen" (p. 219). 
porque es una determinada $\dot{\alpha} \rho \varepsilon \tau \dot{~ o ~ p o r q u e ~ v a ~ a c o m p a n ̃ a d a ~ d e ~}$

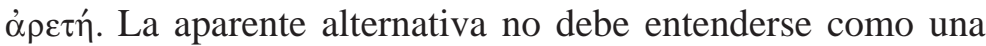
disyunción excluyente interpuesta por Aristóteles, como Wolf interpreta $^{12}$ ni como una restricción mediante la cual Aristóteles querría decir, como Dirlmeier ${ }^{13}$ interpreta. Que la amistad es una virtud y que se comporta como las otras virtudes éticas es algo que se establece tanto en $E N$, II 7, 1108 a 26-30, como en IV, 12, 1126 b 11-25. En el primer pasaje 1108 a 26-30 clasifica Aristóteles la $\varphi \imath \lambda i ́ \alpha$, junto a las demás, como una virtud entre dos extremos y determina el amplio campo en que

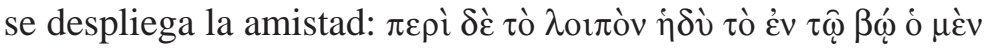

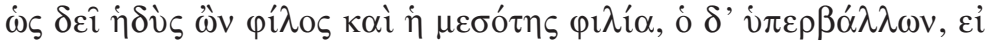

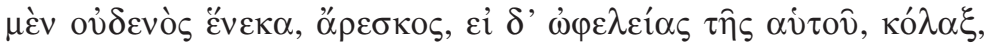

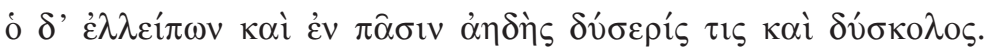
La esfera sobre la cual se extiende la amistad consiste en las

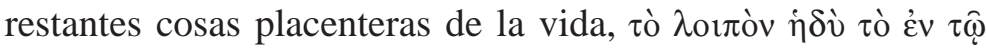
ßíw, es decir, dentro del campo de la amistad no se trata de lo placentero o del placer a que se refiere la templanza, $\sigma \omega \varphi \rho о-$ $\sigma u ́ v \eta$, o el ingenio, $\varepsilon v ่ \tau \rho \alpha \pi \varepsilon \lambda i ́ \alpha$. Aquélla se refiere evidentemente a los placeres corporales, ésta al placer que se disfruta

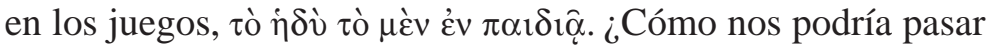
inadvertido el hecho de que lo placentero - como se constata repetidas veces a lo largo de los posteriores libros VIII y IXconstituye un rasgo esencial de la amistad y que desde este pasaje anterior de la Ética queda como tal establecido junto con el objeto y la esfera propios de la amistad?

F. Dirlmeier rechaza la posibilidad de traducir $\varphi \imath \lambda i ́ \alpha$ por "Freundschaft" en los pasajes en que Aristóteles se refiere a ella junto a las demás virtudes éticas. Dirlmeier ${ }^{14}$ cree, en

\footnotetext{
${ }^{12} \mathrm{Ib}$.: "ob die philia selbst eine aretê oder nur ein verwandtes Phänomen ist", pp. 218, 214.

${ }^{13}$ Dirlmeier: "daß wir jetzt nicht an jene Gesellschaftstugend von IV $12 \mathrm{zu}$ denken haben", Nikomachische Ethik, Berlin, Akad.-Verl Berlin, Wiss. Buchges., 1956, p. 510

${ }^{14} \mathrm{Ib} .$, p. $308,34,1$.
} 
efecto, que es absolutamente erróneo traducir el concepto philía en $M M$, I, 31, y en EE, III, 7, 4, por "Freundschaft", en la idea de que Aristóteles en estos pasajes de las Éticas se refiere a un modo de ser o a un hábito diferente de aquel que en los ulteriores tratados sobre la amistad - EN, VIII-IX; $E E$, VII, y

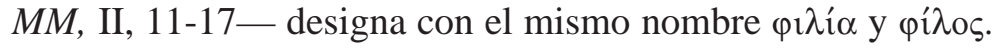
Así pues, propone como traducción de estos conceptos al alemán un término diferente de "Freundschaft" y "Freund", si bien no logra ser consecuente en la traducción del mismo concepto en los pasajes paralelos de las tres Éticas. En EN, II, 7 (1958, p. 40) traduce $\varphi \imath \lambda i ́ \alpha$ y pí $\lambda$ os por "Freundlichkeit" y "freundlich", en EE, II, 3; III, 7 (1962, pp. 24, 59-60) por "Freundschaftlichkeit" y "freundschaftlich" y en $M M$, I, 31 (1956, p. 34) por la expresión "freundschaftliche Aufrichtigkeit" und "aufrichtiger Freund".

En EN, IV, 12 (1958, pp. 88-89), sin embargo, traduce el mismo concepto $\varphi \imath \lambda i ́ \alpha$ por "Freundschaft" y $\varphi$ í $\lambda \circ \varsigma$ por "Freund", sin advertir que en este pasaje se despliega de manera detallada el mismo concepto $\varphi \imath \lambda i ́ \alpha$ que como término medio entre dos extremos había sido esquemáticamente expuesto en II, 7 y que, por tanto, en ambos pasajes se interpreta el mismo concepto. En efecto, en II, 7, 1107 b 14-16 Aristóteles señala en relación con su primera exposición sobre las virtudes éticas: vôv $\mu$ غ̇v oûv

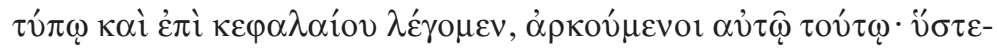

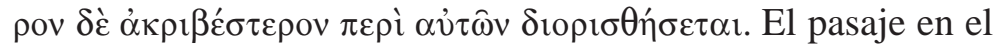

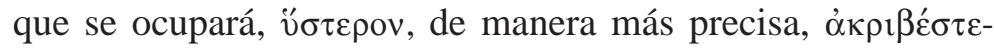
pov, de la amistad y de los extremos contrarios a ella, se encuentra en IV, 121126 b 11-1127 a 12. Los diferentes textos sobre la amistad que se presentan en cada una de las éticas aristotélicas como una primera exposición sobre la $\varphi \imath \lambda i ́ \alpha$ deben interpretarse de manera opuesta a como sugiere Dirlmeier. En efecto, Aristóteles emplea el concepto $\varphi \imath \lambda i ́ \alpha$ en el

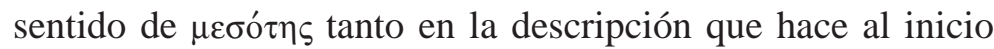
junto a las demás virtudes, como a lo largo del tratado propiamente de la amistad. 
El primer argumento de Aristóteles que fundamenta el tratado de la amistad y establece que la amistad es una especie

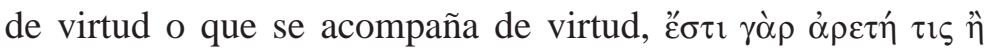
$\mu \varepsilon \tau$ ' $\dot{\alpha} \rho \varepsilon \tau \hat{\varsigma}$, supone la premisa ya establecida de que la amistad es un medio entre dos extremos: en II, 7, y IV, 12 queda-

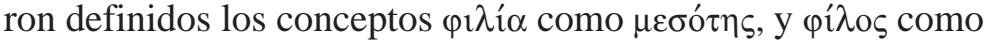
aquél que, siendo agradable y se comporta como conviene, se

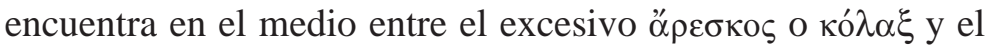

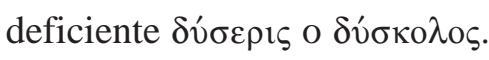

En el segundo tratado sobre el placer EN, X, 3, 1173 b 311174 a 1 trae Aristóteles a la memoria la diferencia expuesta en II, 7, y IV, 12 entre un amigo y un adulador: $\dot{\varepsilon} \mu \varphi \alpha v i \zeta \zeta \varepsilon ı v ~ \delta \grave{\varepsilon}$

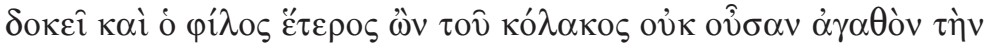

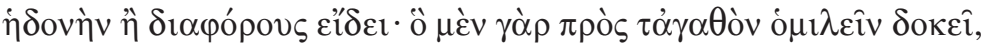

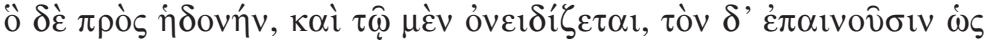

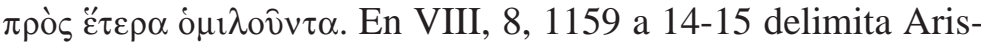
tóteles de nueva cuenta a un adulador de un amigo: i $\pi \varepsilon \rho \varepsilon \chi o ́-$

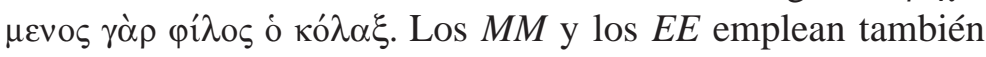
en algunos pasajes el concepto кó $\alpha \alpha \xi$, término en relación con el cual, al igual que en $E N$, también en ellas en un pasaje

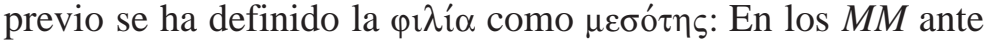
la pregunta de si es difícil o fácil llegar a ser amigo, se

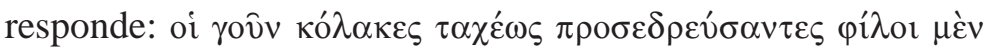

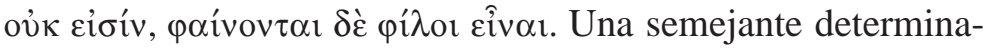
ción del concepto кó $\lambda \alpha \xi$ encontramos en Rhet., 1371 a 24:

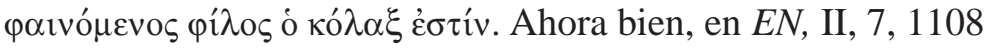
a 28 se nos da el argumento de por qué el adulador se esfuerza en mostrarse demasiado agradable ( $\dot{\pi} \varepsilon \rho \beta \alpha \dot{\alpha} \lambda \lambda \omega v$ ) y en aparentar que es amigo, mediante una fina distinción entre dos modos de ser que caen igualmente en el exceso con respecto a la

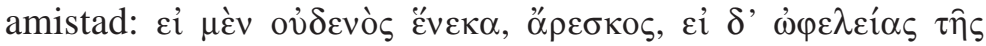
$\alpha$ ¿ $\tau 0 \hat{v}, \kappa o ́ \lambda \alpha \xi$. El adulador se comporta frente a los demás en exceso agradable, porque espera de éstos sacar provecho. $\mathrm{Si}$ se comporta excesivamente amable sin esperar beneficio alguno, no es entonces adulador sino complaciente. En EE, VII, 4, 
1239 a 23-25, ante la pregunta de por qué los amigos de

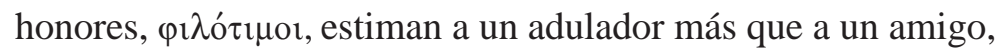
se argumenta de manera semejante mediante la distinción entre una relación de amistad, que se apoya en la igualdad, y una relación de adulación, que implica substancialmente un trato de inferioridad: los que persiguen los honores honran antes a los aduladores, porque un adulador despierta en ellos la impresión de que son queridos y al mismo tiempo superiores, pues

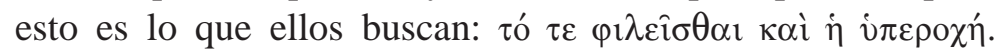
En EN, VIII, 8, 1159a 14-16 se da también la explicación de que la mayoría de los hombres prefieren ser amados antes que amar mediante el argumento del deseo de honores, $\delta i \grave{\alpha} \varphi \imath \lambda o \tau \imath-$

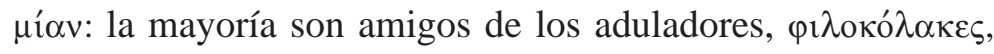
pues el adulador es un amigo en posición de inferioridad o aquel que finge ser inferior y amar más que ser amado: i $\pi \varepsilon \rho-$

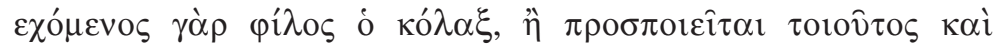

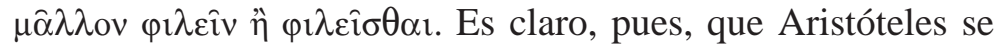
sirve de la definición de la amistad como un modo de ser intermedio entre dos extremos, siempre que hace en otros pasajes la distinción entre un amigo y un adulador o un complaciente. Esta distinción del amigo, pínos, como aquel que es agradable en la medida en que conviene serlo y que se ubica en el medio entre el adulador, кó $\lambda \alpha \xi$, y el malhumorado,

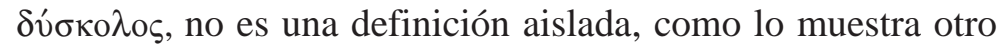
pasaje en VIII, 7, que Aristóteles no tenga presente en el tratado de la amistad. Según este pasaje, 1158a 3, la amistad se da en poca medida entre los de carácter agrio y ancianos,

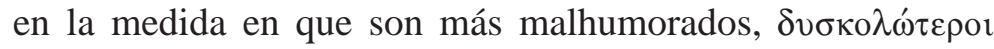
( $\delta \dot{\sigma} \sigma \kappa о \lambda \circ \varsigma_{:}$el otro extremo contrario al amigo, diametralmente opuesto al adulador: $\kappa o ́ \lambda \alpha \xi)$ y encuentran menos placer en la compañía de otros, siendo ésta una característica en alto grado y causa de la amistad.

En EN, II, 7, y IV, 12 se establece evidentemente la naturaleza, el ámbito y el objeto de la amistad. Esta primera determinación de la amistad como virtud debemos tenerla presente 
a lo largo del desarrollo del tratado de la amistad en los libros VIII y IX. Pues, en primer lugar, en II, 7, 1108a 14, Aristóteles establece como objeto de la amistad lo placentero en

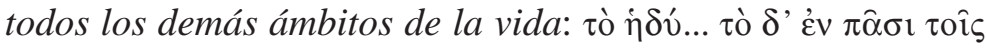

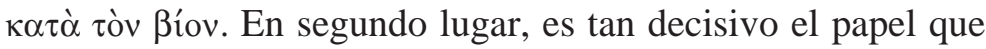
Aristóteles atribuye a lo placentero a lo largo de los libros VIII y IX, que el placer - especialmente el disfrute de la compañía - constituye un rasgo esencial de la amistad: 1158

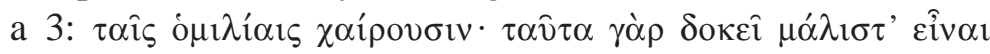

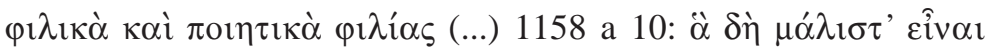
ठокєî amplio campo en que se da el objeto de la amistad como "en todos los demás ámbitos de la vida", así también se determina en VIII, 1 el carácter indispensable de la amistad para la vida:

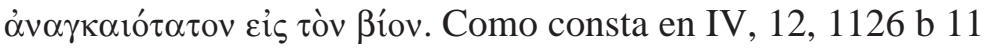
Aristóteles delimita con otros términos el campo en el que se ejerce la amistad, considerándola, pues, desde el punto de vista de la actividad que implica la convivencia de los amigos:

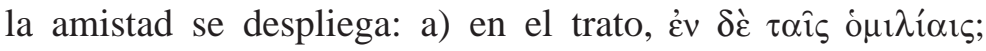

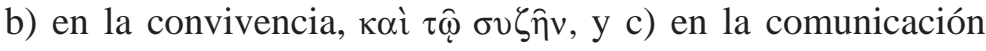

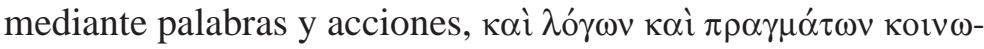
veîv. Pues bien, lo común, tò korvóv, el trato con los amigos,

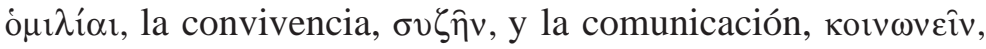
constituyen un criterio esencial a lo largo de los libros VIII y IX en la delimitación de la amistad, como ha sido mostrado previamente y lo confirman otros pasajes: 1158 a 3: бокєî

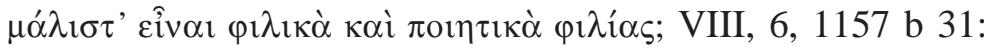
"Pues nada es más propio entre los amigos que la convi-

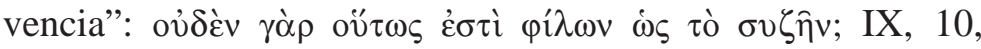
1171a 2: "Pues <afirmamos que> esto parecía lo más pro-

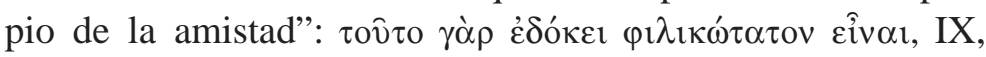
12, 1171 b 32 "Así también para los amigos lo más preferible es la convivencia, pues la amistad es comunidad": ov́ $\tau \omega$

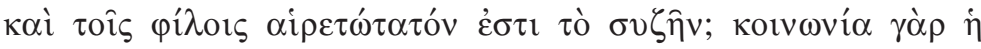
$\varphi \imath \lambda i ́ \alpha$. 
Es evidente, por tanto, que en los pasajes anteriores $E N$, II, 7, y IV, 12, se determina el objeto y la esfera de la amistad en tanto que virtud y término medio entre dos extremos, y que esta definición como la definición de un amigo constituyen el marco de referencia dentro del cual Aristóteles despliega su teoría de la amistad posteriormente en los libros VIII y IX. No

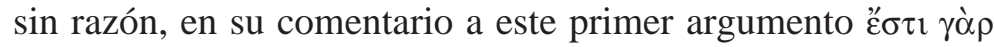
$\dot{\alpha} \rho \varepsilon \tau \eta \dot{~} \tau 1 \varsigma \hat{\eta} \mu \varepsilon \tau$ ' $\dot{\alpha} \rho \varepsilon \tau \eta ิ \varsigma$, Aspasio sitúa su interpretación en el contexto de aquellos pasajes previos en que ha sido definida

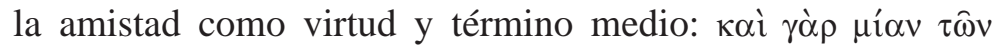

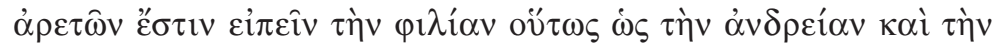

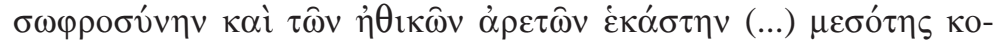

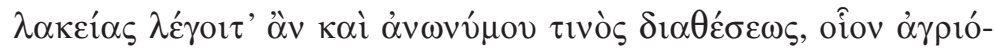

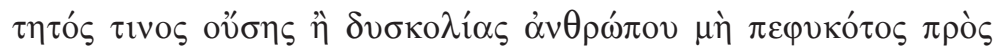

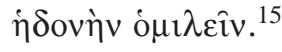

Por otra parte, tan absurdo es poner en duda que la $\varphi \imath \lambda i ́ \alpha$ es

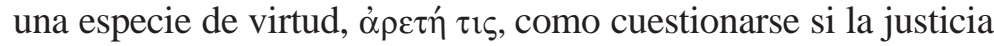
es o no una virtud. Pues, la justicia evidentemente es una virtud $\mathrm{y}$, como hemos visto, la justicia y la amistad se analizan de manera paralela y tienen tanto en común, que, como se afirma en $E E, 1234$ b 31, o son lo mismo o están muy cerca la una de

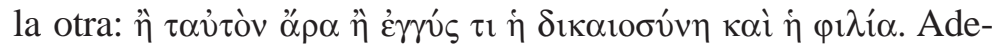
más, si no partimos de la premisa de que la amistad es ante todo una virtud, no podremos comprender en absoluto la teoría aristotélica de la amistad, pues el fundamento sobre el cual ésta se construye es precisamente la virtud. Como podrá desprenderse a partir de la lectura de este artículo, tres tesis aproximadamente constituyen el fundamento y el pilar de la teoría aristotélica de la amistad: a) la amistad en sentido estricto y primario

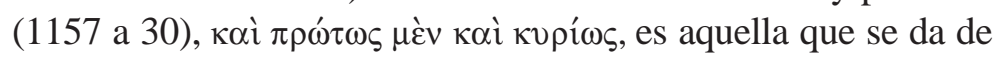

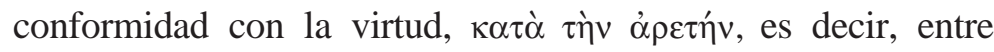

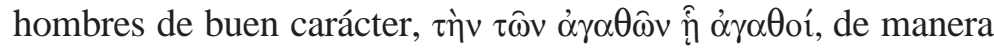
que las demás clases de amistad no son por sí mismas tales,

${ }^{15}$ Cfr. Aspasio, CIAG, XIX, pp. 158-159. 
sino sólo en la medida en que guardan semejanza, $\kappa \alpha \theta$ ' ó $\mu$ oró$\tau \eta \tau \alpha$, con aquélla; b) la amistad de un hombre consigo mismo, $\varphi \imath \lambda \alpha v \tau i \alpha$, se da solamente en el hombre excelente, $\sigma \pi 0 v \delta \alpha i o s$, pues éste posee la virtud; c) el sentimiento de afecto y de amistad hacia los demás tiene como fuente y principio el sentimiento de afecto hacia uno mismo (cfr. nota 38), de manera que la amistad con respecto a los demás depende y procede de la amistad de uno en relación consigo mismo.

Las preguntas que habría que formular y responder, en todo caso, serían: ¿qué clase de virtud es la amistad, y en qué se diferencia de las demás virtudes éticas? Otra manera de plantear lo mismo, sería, quizá: ¿qué debemos entender por la

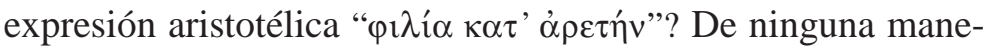
ra se trata de una pregunta banal, pues la respuesta a dicha pregunta podría arrojar mucha luz acerca de la estructura de los tratados sobre la amistad, no sólo en relación con su significado y el orden que guardan, como un todo, dentro de los escritos de ética, sino también en relación con la estructura propia que internamente los constituye. Si bien este problema merece un desarrollo posterior, baste aquí con esbozar una posible respuesta. Con la expresión "la amistad según la vir-

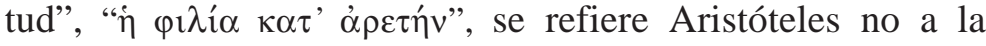
posesión de una única virtud — distinta de las demás virtudes éticas-, ni a la posesión de una virtud complementaria o diferente de la amistad misma. La "amistad según la virtud" implica la posesión y la actualidad de todas las virtudes éticas. El amigo en el sentido aristotélico, el verdadero amigo, ò $\delta$ ' $\dot{\alpha} \lambda \eta \theta$ vòs $\varphi$ ítos, o amigo en sentido primario, $\pi \rho \omega ́ \tau \omega \varsigma$, es aquel que se conduce no solamente según la justicia, sino también de conformidad con la valentía, la templanza, la liberalidad, la mansedumbre y, en general, de acuerdo con todas las demás virtudes. Pues no es posible imaginar, desde la perspectiva de la teoría de Aristóteles, a ninguno que, siendo amigo, al mismo tiempo no se condujese de manera valiente: $E N, 1169$ a 18:

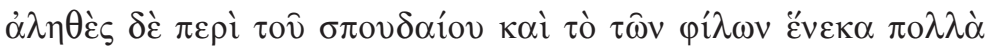




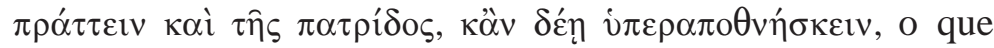

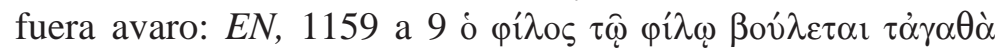

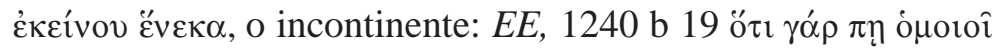

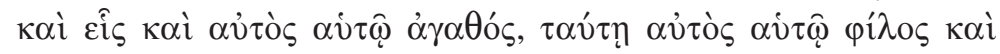

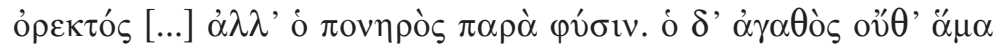

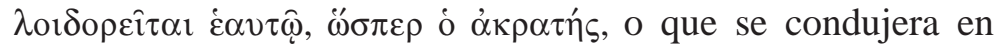
general según cualquiera de los demás modos de ser contrarios al término medio. En este sentido, el tratado de la amistad constituye el punto culminante de la teoría de las virtudes éticas de Aristóteles. Y lo que el tratado de la amistad es al tratado de ética en su conjunto - el eslabón que dentro de su teoría une la vida práctica y la vida contemplativa-, es el tratado de la philautía al tratado de la amistad en su conjunto: el punto culminante, central y más importante dentro de la teoría aristotélica de la amistad, lo constituye, en efecto, el tratado sobre la amistad de uno consigo mismo.

Por otra parte, la amistad también se manifiesta en cada una de las formas de gobierno en la misma medida en que en ellas se manifiesta lo justo; y ambas condiciones, tanto la amistad como lo justo, se dan en la misma medida en que en un gobierno gobernantes y gobernados participan de algo en común. En una tiranía, por ejemplo, hay poca o ninguna amistad, como tampoco hay justicia, porque entre gobernante y gobernados no hay nada en común. En las democracias, en cambio, se dan condiciones más favorables para la amistad y la justicia, en cuanto que los ciudadanos, siendo iguales, poseen muchas cosas en común. ${ }^{16}$ Visto, pues, desde una pers-

${ }^{16}$ EN, VIII, 13, 1161 a 32: "En las tiranías, en efecto, no hay amistad o hay muy poca. Pues en aquellas constituciones en las que no hay nada en común entre

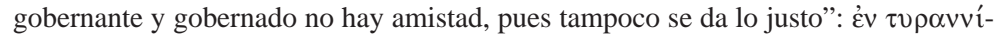

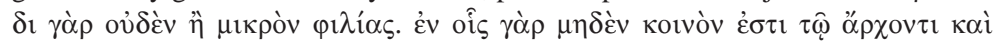

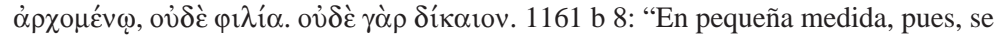
dan en las tiranías la amistad y lo justo, en las democracias, en cambio, se dan en mayor medida. Pues poseen los ciudadanos muchas cosas en común, dado que son

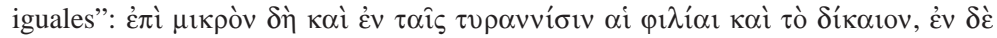

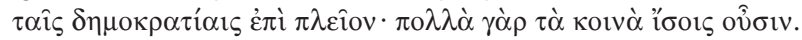


pectiva general, hay tanto más justicia y amistad entre los miembros de una comunidad, cuanto mayor es el grado de participación en ella de los miembros que la componen. Por esa razón, en la familia, dado que los hermanos poseen todas las cosas en común, se alcanza la mayor unidad. Ante todo, los hermanos tienen en común los mismos padres, comparten también la educación desde la infancia, se han criado juntos y son semejantes en carácter. ${ }^{17}$ Entre ellos hay por esa razón igualdad, de modo que su amistad es semejante a la amistad entre compañeros. Desde este punto de vista, pues, hay diversas clases de amistad, que se dan o bien entre iguales o bien entre desiguales. Entre iguales en el ámbito privado, como los camaradas y los hermanos en una familia, o en el ámbito público, como los ciudadanos en su relación de unos con otros. Entre desiguales en la esfera política, por ejemplo, como los gobernantes y gobernados, o, en el ámbito privado, como la relación entre padres e hijos, y entre marido y mujer.

Consideremos a continuación las causas en las que se funda según Aristóteles toda amistad y las causas por las que se destruye; asimismo, los fundamentos de la amistad política, la amistad por parentesco, y, después, la teoría aristotélica acerca de la amistad de un hombre consigo mismo.

a) Causas en las que se funda la amistad y causas por las que se destruye

Como es habitual en Aristóteles, al abordar el examen de una materia comienza, por lo regular, por considerar las aporías o

\footnotetext{
${ }^{17} E N$, VIII, 14, 1162 a 12-14: "En la medida en que son más familiares y se quieren entre sí desde el nacimiento, y en la medida en que, los que proceden de los mismos padres, son más semejantes en carácter, se han criado juntos y han

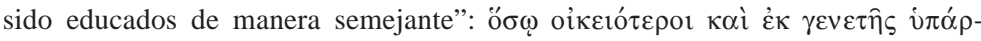

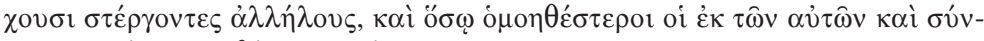

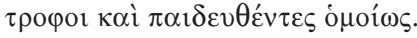


dificultades que su estudio plantea, o bien, las opiniones que acerca del mismo asunto han expuesto sus antecesores. En el caso que nos ocupa, el punto de partida nos es dado mediante las dos grandes posturas que intentan responder a la pregunta qué cosa es la amistad. Algunos la consideran como una especie de semejanza (ómotó $\rceil \tau \alpha \dot{\alpha} \tau \imath v \alpha$ ) y tienen por semejantes a los amigos. ${ }^{18}$ Otros por el contrario afirman que la amistad no puede darse entre semejantes, pues entre dos hombres que desempeñan el mismo oficio hay siempre rivalidad. Algunos buscan una explicación más profunda e intentan fundamentar la causa de la amistad en los fenómenos naturales, argumentando, unos, que la amistad se da entre contrarios, otros, que se da entre semejantes. Eurípides, por ejemplo, dice: "después que se ha secado, la tierra ama la lluvia", "el venerable cielo, pletórico de lluvia, ama caer sobre la tierra"; 19 y es opinión de Heráclito que "lo contrario es lo que conviene", que "la más bella armonía procede de los tonos diferentes" o también que "todas las cosas nacen de la discordia". ${ }^{20}$ Por el contrario, Empédocles sostiene que la amistad se funda en cierta igualdad, al afirmar que "lo semejante tiende hacia lo semejante". ${ }^{21}$

Pero tales consideraciones de orden físico, según Aristóteles, escapan al propósito de este tratado. La esfera propia de la amistad se limita, en efecto, a una relación estrictamente

\footnotetext{
${ }^{18} E N$, VIII, 2, 1155 a 34. De donde se dice "dios conduce al semejante hacia

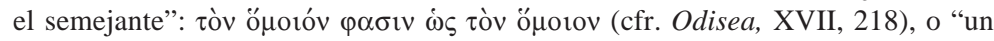

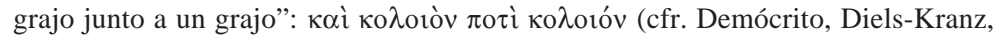
fr. 164).

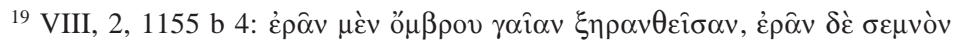

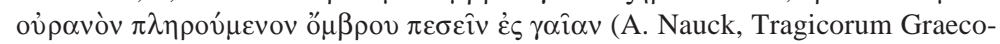

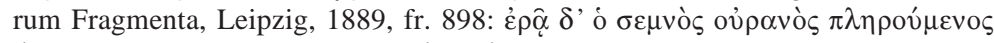

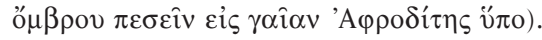

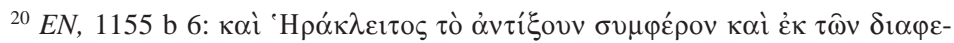

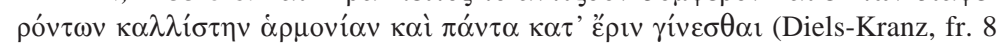
y 80$)$.

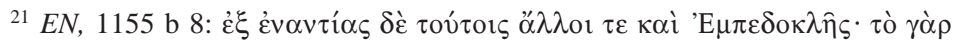

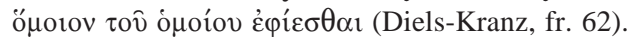


humana y concierne tanto al carácter como a las pasiones del hombre.

Podría sorprender a uno el hecho de que Aristóteles integre en un principio como parte de la investigación, algo que más tarde él mismo ha de hacer a un lado porque en su opinión - cosa que naturalmente sabe de antemano- no es pertinente a la materia. Surge aquí, pues, la pregunta: ¿para qué considerar en una investigación algo que, de antemano se sabe, cae fuera del dominio de aquello que se investiga? Para responder a esta pregunta conviene advertir, en primer lugar, que las reflexiones de los filósofos presocráticos o las opiniones anteriores vertidas sobre el tema sirven de punto de partida a la investigación aristotélica. Esto forma parte de su método habitual, el cual consiste por lo regular en considerar primero aquellas cosas que se han dicho en torno al tema en cuestión o bien en plantear las aporías o dificultades que han de resolverse ulteriormente en el curso de la investigación.

Aquellos que no exponen de antemano las dificultades que plantea una investigación — así dice en Metafísica, III— son semejantes a los que ignoran hacia dónde conviene caminar y tampoco saben si alguna vez han encontrado o no lo buscado. Para ellos el fin no es evidente, como sí lo es, en cambio, para el que antes ha planteado las aporías. Pero, además, es necesario que tenga mejor condición para juzgar el que ha escuchado, tal como se escucha a las partes en un pleito, todos los razonamientos que se discuten. ${ }^{22}$

Así pues, de esta manera se explica por qué son consideradas por Aristóteles las opiniones vertidas por sus antecesores y las aporías o dificultades que plantea el estudio de una materia en particular. No está por demás, a este respecto, recordar otro

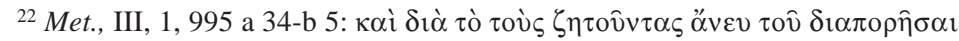

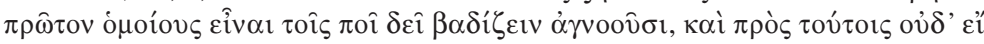

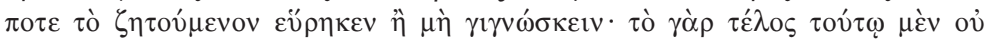

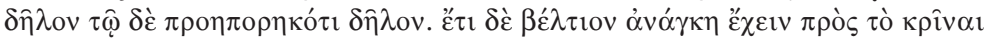

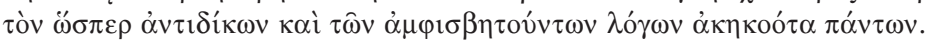


pasaje de la Metafísica, en el que Aristóteles expresa en relación con tales consideraciones su punto de vista. Dice al inicio del libro II: Es justo tener agradecimiento no sólo hacia aquellos cuyas opiniones podría uno compartir, sino también hacia los que han hecho declaraciones de manera más superficial; pues también estos contribuyeron en algo, ya que pusieron en movimiento desde antes nuestro hábito de pensar. En efecto, si no hubiera existido Timoteo, no tendríamos mucha melodía; pero, si no hubiese existido Frinis, no habría existido Timoteo. ${ }^{23}$

Las dos hipótesis opuestas acerca del origen de la amistad - en el sentido de que ésta se da o entre seres semejantes o entre contrarios - anticipan en cierto modo una posterior distinción aristotélica de la amistad entre semejantes y desemejantes, por un lado, y, por otro, la amistad fundada en el bien o en el placer y la fundada en la utilidad. ${ }^{24}$ Sin embargo el despliegue que hace Aristóteles de tales hipótesis referidas al ámbito de la física, le permiten sobre todo establecer una clara delimitación: no corresponde a la ética buscar la explicación de la amistad en los fenómenos naturales. El origen de la amistad habrá que buscarlo no afuera sino dentro del hombre,

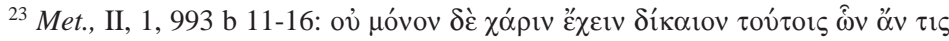

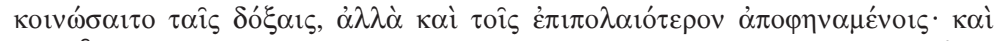

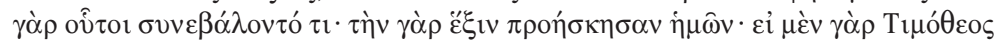

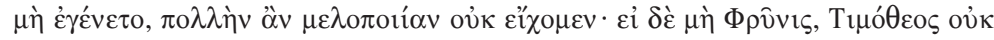

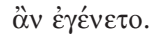

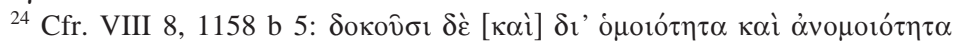

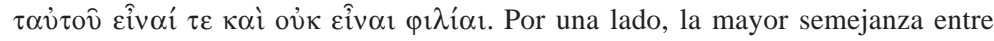

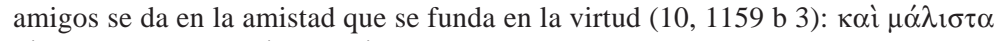

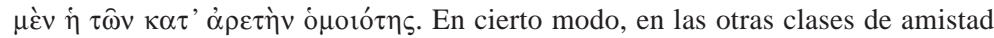
se da también una especie de semejanza, en la medida en que la relación de

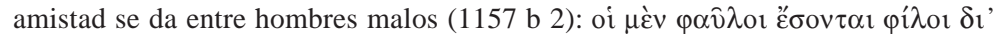

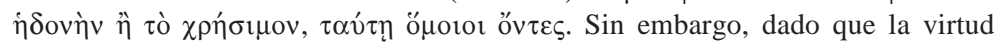
tiene una sola forma, pero el vicio muchas, entre los malos se da también la desemejanza. La mayor desemejanza se da en la amistad entre los contrarios, en aquellos que establecen en la utilidad el motivo de su amistad, como entre el

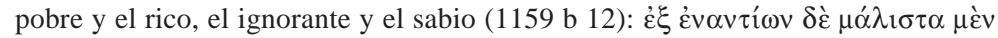

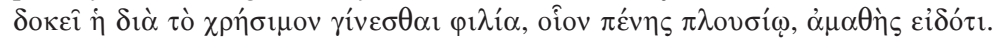


en relación con su carácter y sus pasiones, pues éste es el ámbito de la ética. De modo que las dificultades que nos presenta su estudio y a cuya solución tiende esta investigación, han de ser del mismo género y han de referirse a la naturaleza humana. En primer lugar, en efecto, se plantean las siguientes dificultades: ¿se da la amistad en todos los hombres o no es posible que los malos sean amigos? Por otra parte, ¿hay una sola especie de amistad o hay varias?

Para responder a estas preguntas, Aristóteles establece, en primer lugar, cuál es la naturaleza de aquello que despierta en nosotros un sentimiento de amistad, es decir, cuál es el objeto por el que nos vemos inclinados a buscar una relación de amistad. Pues bien, aquello que nos mueve a sentir afecto por otro, lo querible, lo amable ( $\tau$ ò $\varphi \imath \lambda \eta \tau o ́ v)$, es de tres clases: lo bueno, lo agradable y lo útil. Pues cuando creemos que hay en el otro algo bueno, algo agradable o provechoso, nos vemos inclinados hacia él, movidos por un sentimiento de amistad. ${ }^{25}$ Análogamente, llegamos a ser objeto de ese sentimiento de amistad cuando el otro descubre en nosotros algo amable, sea bueno, placentero o provechoso. Sin embargo, uno de los rasgos más característicos de la amistad no es el simple hecho de sentir empatía o desear el bien al amigo por el amigo mismo, sino que el sentimiento de amistad sea recíproco y, sobre todo, que la empatía recíproca no pase inadvertida a ninguno de los dos. La amistad, en efecto, se define especialmente como una actividad y consiste en hacer el bien recíprocamente mediante hechos y palabras. ${ }^{26}$ Así pues, anhelar el

\footnotetext{
${ }^{25}$ Sin embargo, el plano en que se ubica lo útil es diferente de aquel en que se encuentran lo bueno y lo placentero; pues útil es aquello por medio de lo cual obtenemos un bien o un placer, de manera que, aquello que nos mueve a sentir amistad como fin, es lo bueno y lo placentero: $E N$, VIII, 2, 1155 b 19: $\delta$ ó $\xi \varepsilon 1 \varepsilon \delta$ '

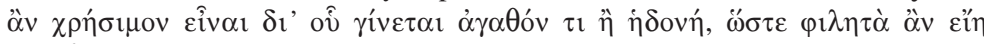

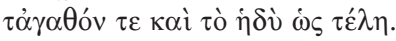

${ }^{26} E E$, VII, 4, 1239 a 33: "Corresponde a la amistad el sentir afecto antes que

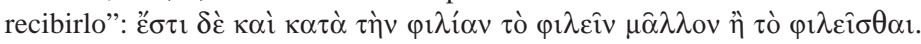


bien del otro sin que el otro, a su vez, corresponda este sentimiento, o, aun correspondiéndolo, el que uno de los dos desconozca la disposición favorable y recíproca que se da en el otro, no implica todavía amistad. Hay entre ellos, sí, benevolencia, pero no amistad. El anhelo de amistad nace pronto y puede darse aun con respecto a aquellos con los que jamás hemos tenido contacto; la amistad, en cambio, nace sólo mediante el contacto y crece con la confianza. Pero la confianza, a su vez, no crece sino a través del trato y el tiempo. ${ }^{27}$

De las tres causas que originan en el hombre el sentimiento de amistad, hace derivar Aristóteles igualmente tres especies de amistad. Así, la primera especie se funda en el bien; la segunda en el placer, y la tercera en la utilidad. En cada una de ellas se da el sentimiento recíproco de amistad sin que éste pase inadvertido, de manera que aquellos que sienten amistad entre sí, anhelan los unos a los otros el bien, en la misma medida en que sienten amistad por el otro. Los amigos cuya amistad se funda en la utilidad sienten amistad recíproca, no por causa de sí mismos, sino en la medida en que tanto el uno como el otro reciben recíprocamente un beneficio. Lo mismo sucede entre los amigos cuya amistad se funda en el placer. $\mathrm{Ni}$ éstos ni aquéllos sienten amistad por causa del amigo mismo, pues, en un caso, sienten amistad no porque el amigo sea por sí mismo bueno, sino porque resulta útil y reporta un beneficio; en el otro caso, no por su propio carácter o porque sea por sí mismo agradable, sino porque procura cierto placer. Sin embargo, en sentido estricto, la amistad consiste en anhelar el bien al amigo por causa de él mismo, es decir, por su carácter, por ser él aquello que es y no por otra razón; de modo que aquellas dos son amistades por accidente, pues en ellas no es el modo de ser del amigo, sino el interés o el placer, lo que despierta el sentimiento de amistad.

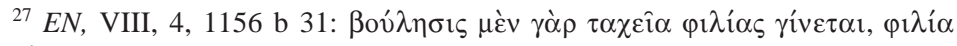
$\delta$ ' ov้.
} 
Ello explica también por qué razón tales amistades se disuelven fácilmente, pues la causa en que se fundan es inestable. En efecto, tanto el placer como lo útil cambian constantemente y unas veces son una cosa otras veces otra. De manera que, si deja de existir la causa en que una relación se funda, deja de existir con ello también la amistad, pues la amistad existe en relación con la causa.

Los amigos cuya amistad se funda en el bien se comportan entre sí de manera diferente a aquellos cuya amistad descansa en la utilidad o en el placer. El rasgo distintivo de su comportamiento radica en que, a diferencia de la relación que se da entre estos últimos, no exigen del amigo nada externo. Pues el sentimiento de amistad en cada uno de ellos se cifra en el anhelo del bien para el amigo, por causa del amigo mismo.

Uno podría, sin embargo, preguntarse ¿qué quiere decir Aristóteles exactamente con la frase anhelar el bien del amigo por causa del amigo mismo? En ninguna parte de su obra encontramos una respuesta explícita o directa a esta posible pregunta. Con todo, un pasaje de la Ética Nicomaquea en el que se discute por qué la mayoría de los hombres anhelan ser amados antes que amar y recibir honores antes que honrar a otro, nos proporciona mediante el modelo del afecto materno un ejemplo del sentimiento desinteresado en que se funda la amistad verdadera, sentimiento que, en el fondo, consiste precisamente en alegrarse por el bien del amigo, independientemente de que éste lo sepa y esté en condiciones o no de correspondernos con su afecto. Según este pasaje, por ambición, la mayoría de los hombres prefiere ser querido antes que querer. La razón es que el ser querido parece ser un indicio de superioridad, y la consecuencia lógica es que la mayoría de los hombres sean amigos de los aduladores, pues un adulador es un amigo en posición de inferioridad o que finge ser inferior y amar más que ser amado. Por otra parte, ser querido y recibir una honra parecen ser condiciones semejantes entre sí, por eso la mayoría aspira también a recibir 
honores. Pero lo que los mueve no es el honor por sí mismo, como tampoco a los aduladores los mueve la amistad por sí misma. Un adulador es aquel que finge sentir amistad con la esperanza de sacar un provecho; los que buscan ser honrados, por su parte, lo hacen ya sea con la esperanza de obtener, gracias al reconocimiento, un beneficio ulterior, o simplemente para confirmar la opinión que tienen de sí mismos, de que son hombres buenos. Es claro, pues, que ni en un caso ni en otro se busca la amistad o la honra por sí mismas, sino por accidente. El amigo verdadero, en cambio, es aquel que elige la amistad y al amigo por sí mismos, es decir, aquel que no busca ni espera un beneficio ulterior ni ser honrado por el otro. Éste es el sello principal de la amistad, que consiste especialmente en querer más que en ser querido. Una muestra de ello es que las madres se alegran por el simple hecho de amar a los hijos. Pues algunas los dan en adopción y los aman en tanto que tienen conocimiento de ellos, sin buscar ser amadas en correspondencia a su afecto, si ambas cosas no han de ser posibles; por el contrario, parece que les basta el ver que se encuentran bien y los aman aun si ellos, por ignorancia, no restituyen cuanto se le debe a una madre. ${ }^{28}$ Así pues, mediante ese sentimiento de amistad desinteresado que una madre muestra por sus hijos, podemos entender mejor lo que Aristóteles quiere decir con la frase anhelar el bien del amigo por causa del amigo mismo.

Con ello queda también claro en qué se diferencia la amistad que se da entre hombres de buen carácter de las amistades que se fundan en la utilidad y en el placer. Los amigos por utilidad no anhelan el bien del amigo por causa del amigo mismo, sino que lo hacen en cuanto que esperan obtener de él

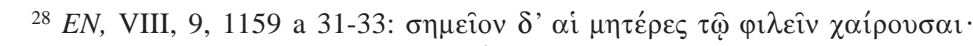

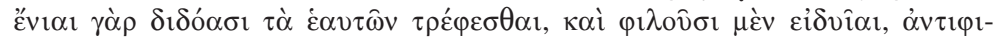

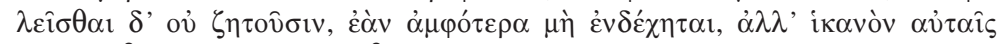

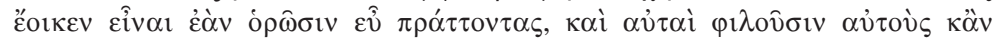

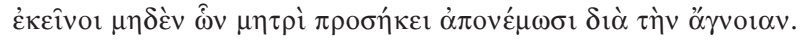


un beneficio. Esta clase de amistad se da en la mayoría de los hombres. Los amigos cuya amistad se funda en el placer, de manera semejante sienten amistad por el otro, no por causa del amigo mismo, sino en la medida en que éste es capaz de procurarles un placer; dicha amistad se da sobre todo entre los jóvenes; y tanto ésta como aquélla son inestables y admiten el reproche entre las partes, si una de éstas no se siente correspondida en el beneficio o en el placer esperado; cosa que no sucede en la amistad primera, porque en ella los amigos sienten amistad recíproca por el amigo mismo, sin buscar un beneficio o placer a cambio del sentimiento de amistad proferido. La virtud propia de los amigos, en efecto, consiste en sentir amistad por el otro. ${ }^{29} \mathrm{Y}$ esto se da mutuamente en la amistad primera. Además, dado que esta amistad se da entre hombres buenos, hombres que no cambian de parecer a cada momento y cuyo carácter es estable, se sigue que esta clase de amistad es por necesidad duradera. Sin embargo, dado que la virtud ética no es fácil de alcanzar, la amistad que se funda en ella y que se da entre los hombres mejores, es igualmente rara; lo cual no obsta, según la teoría de Aristóteles, para que nos esforcemos por conseguirla. Pues el fin de la ética radica precisamente en la acción. No indagamos qué cosa es la virtud sólo para saberlo, sino para ser de esa cualidad; ni investigamos qué cosa es la justicia para saber teóricamente en qué consiste, sino más bien para llegar a ser justos, pues el fin no es el conocimiento sino la acción. Así también en el caso de la amistad, no se trata de saber en qué consiste ser un amigo verdadero sino en llegar a serlo. ${ }^{30}$

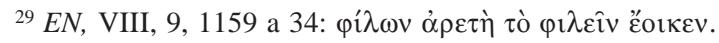

${ }^{30}$ Cfr. $E N$, I, 1,1095 a 5 "Puesto que el fin no es el conocimiento sino la

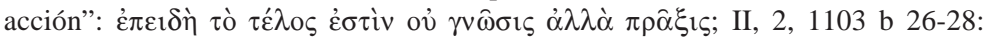
"Puesto que el presente tratado no tiene como finalidad la contemplación, como es el caso de las demás ciencias (pues no investigamos para saber qué es la virtud, sino para llegar a ser buenos...)" 'E $\pi \varepsilon i$ ov̉v $\dot{\eta} \pi \alpha \rho \circ \hat{\sigma} \sigma \alpha \pi \rho \alpha \gamma \mu \alpha \tau \varepsilon i ́ \alpha$ ov่

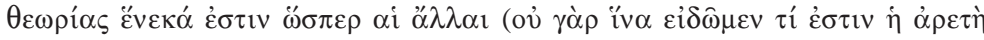




\section{b) Amistad por parentesco}

Para explicar esta especie de amistad — la que se funda en la virtud - y la fuente de donde procede no sólo ésta, sino en general toda relación y todo sentimiento de amistad hacia los demás, es preciso analizar tanto la relación que se da entre parientes, como la amistad que se produce en uno consigo mismo. Como veremos en seguida, aquellas condiciones y sentimientos de amistad que se dan en la relación entre padres e hijos parecen darse análogamente en la relación de un individuo consigo mismo, y tales condiciones y sentimientos, a su vez, permiten definir todos los demás tipos de amistad. ${ }^{31}$

La relación entre parientes se da en distintos niveles y latitudes. Por un lado, tras la unión de marido y mujer a que da lugar la naturaleza (y esto no solamente en los hombres, sino también en los demás animales y plantas) ${ }^{32}$ con el nacimiento de los vástagos se engendra la relación entre padres e hijos, y, posteriormente, la relación de los hijos entre sí. La diferencia entre los tipos de amistad que se producen en la familia, corresponde a los diferentes tipos de afecto que se engendra

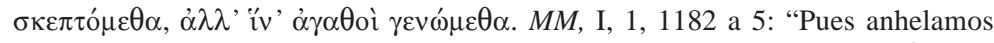

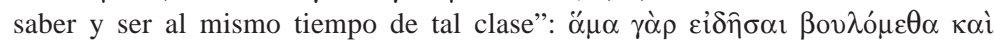

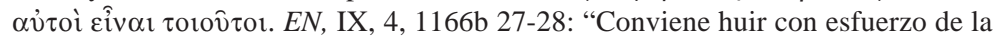

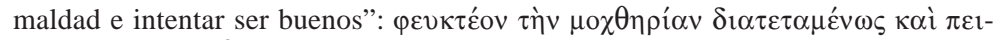

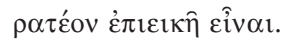

${ }^{31}$ Cfr. EE, VII, 10, 1242 a 40-1242 b: "Por eso en primer lugar en la casa se dan los principios y las fuentes de la amistad, de la constitución política y de lo justo".

${ }^{32}$ Pol., I, 2, 1252 a 26-30: "Es necesario, pues, que en primer lugar se unan aquellos que no pueden vivir el uno sin el otro, como la hembra y el macho, en vista de la reproducción (y esto no como resultado de una elección, sino como sucede en los demás animales y plantas, en los que es natural que cada uno tienda

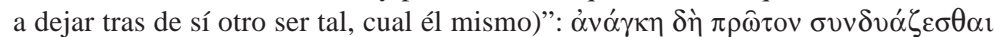

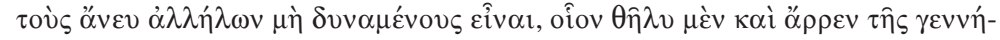

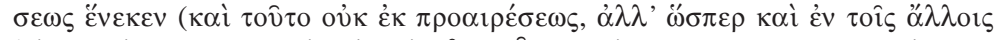

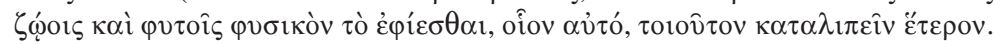


entre las partes que la componen. Así pues, dado que el sentimiento de amistad que se da entre marido y mujer difiere específicamente de aquel que se da entre padres e hijos y del que se da también entre hermanos, de tal variedad de afectos resultan en primer término tres relaciones diferentes de amistad. La amistad entre hermanos descansa fundamentalmente en la igualdad y se parece a la relación entre camaradas. La relación entre padres e hijos es una relación de superioridad semejante a la de gobernante y gobernado, a la de bienhechor y favorecido (pues los hijos han recibido de los padres los mayores bienes) y la relación entre marido y mujer, si bien se funda en cierta superioridad y llega a ser aristocrática, según la virtud de cada uno de los dos, también se asemeja a una amistad política, es decir, como la que se da entre ciudadanos libres e iguales. ${ }^{33}$

Pero tampoco la correspondencia que se da entre unos y otros por lo que respecta al afecto o al sentimiento de amistad llega ser semejante. ${ }^{34}$ Los progenitores, por ejemplo, aman a sus hijos como si fuesen una parte aunque separada de sí mismos, y los hijos a los padres como siendo una parte que procede de ellos; con todo, los progenitores saben que los hijos proceden de ellos, más que los hijos saben que proceden

${ }^{33}$ Cfr. EE, VII, 3, 1238 b 23-25: "Es diferente la amistad entre padre e hijo, varón y mujer. Ésta es como la amistad entre gobernante y gobernado, aquélla

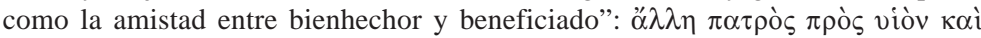

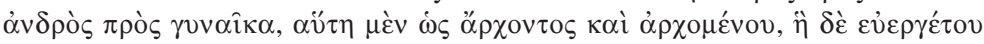

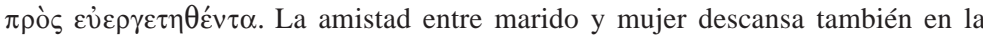
utilidad, pues, como los contrarios, ambos se necesitan mutuamente: VII, 4, 1239

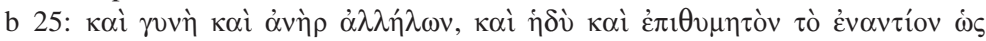

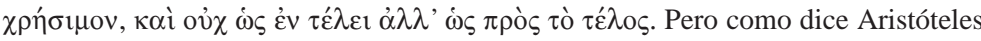
en $E N$, VIII, 14, 1162 a 24, entre ellos se da también lo agradable, y si ambos son buenos, la amistad puede fundarse también en la virtud, pues a cada uno correspon-

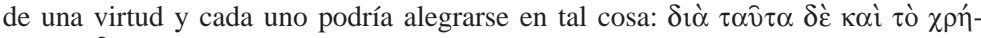

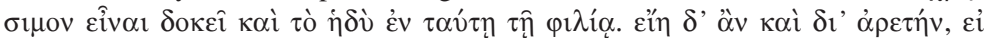

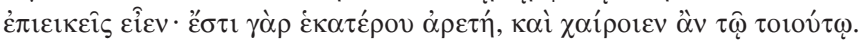

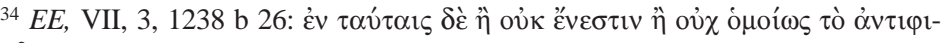
$\lambda \varepsilon \hat{\imath} \sigma \theta \alpha \mathrm{l}$. 
de sus padres. Entre ellos se da una relación tan estrecha como la que se da entre el que produce una obra y la obra engendrada, de manera que el padre está más estrechamente unido al hijo, igual que el productor está más cerca de la obra, en la medida en que la obra le pertenece y es una parte de él, pues lo que procede de una cosa es propiedad de esa cosa de la que procede, como los dientes, las uñas o el pelo, los cuales pertenecen al que los posee; en cambio, a la obra producida no le pertenece el productor del cual ella procede, o le pertenece menos. ${ }^{35}$ La diferencia estriba también en la cantidad de tiempo. Los padres aman a sus hijos tan pronto como éstos nacen, los hijos en cambio aman a sus padres después que ha transcurrido el tiempo y han adquirido conocimiento y percepción. ${ }^{36}$ Los padres sienten amistad, pues, hacia sus hijos como hacia sí mismos, pues los que proceden de ellos son como otros mismos, por haber sido separados. Ésta es la razón también por la cual las madres aman a sus hijos más que los padres, en la medida en que consideran al hijo más como una obra suya; pues juzgan la obra por la dificultad, y una madre sufre más en relación con el nacimiento del hijo. ${ }^{37}$

Conviene aquí llamar la atención sobre la analogía de la que se sirve Aristóteles para ejemplificar y establecer la causa en que se funda el sentimiento de amistad de los padres - y sobre todo de las madres - hacia los hijos; se trata de una analogía que, al igual que la amistad que se da en un hombre

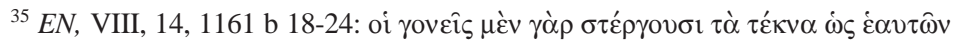

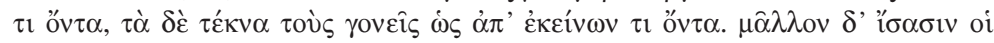

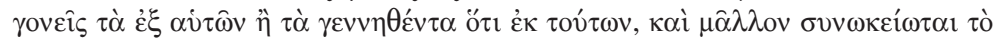

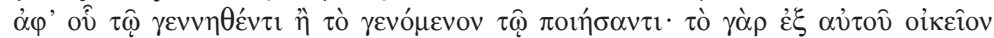

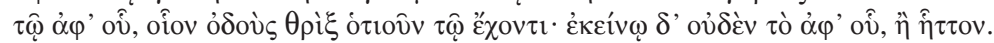

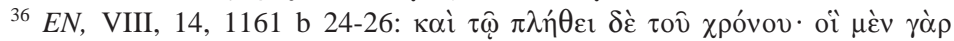

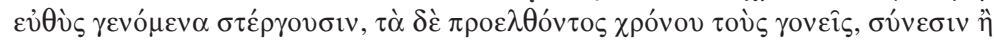

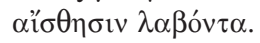

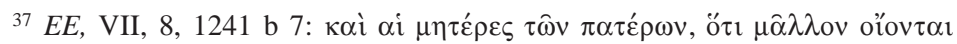
$\alpha$

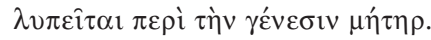


con respecto a sí mismo, remite al origen y a la fuente de todas las demás especies de amistad que se dan en una comunidad. Como veremos más adelante, ese amor que los padres prodigan a sus hijos - en cuanto que estos devienen en una extensión de su propio ser o como otros mismos aunque separados de ellos - es análogo al afecto que llega a sentir un hombre con respecto a sí mismo, especialmente si por su carácter es un hombre bueno. Y ese sentimiento de amistad de uno consigo mismo es modelo, principio y fuente de todas las demás formas de amistad. ${ }^{38}$

Así pues, volviendo al tema de la amistad por parentesco, los hijos aman a sus padres porque de ellos han nacido, y los hermanos por ser idénticos sienten una inclinación de amistad entre sí, dado que han nacido de los mismos progenitores; pues, el que cada uno de ellos sea idéntico en relación con sus padres, hace que ellos mismos sean idénticos los unos a los otros. ${ }^{39}$ Dicha identidad se manifiesta, por ejemplo, mediante tales expresiones: "la misma sangre", "la misma raíz". De manera que son en cierto modo lo mismo, sólo que en individuos separados. ${ }^{40}$ Los primos y los demás parientes se encuentran unidos a partir de los hermanos, en la medida en que proceden de la misma raíz, y unos son familiares más cercanos, otros más lejanos, según la cercanía o lejanía con respecto a su primer fundador.

\footnotetext{
${ }^{38} E N$, IX, 4, 1166 a 1: "El sentimiento y las muestras de amistad hacia los amigos y aquellas características por las cuales se definen las amistades, parecen tener su origen en los sentimientos de amistad de un hombre en relación consigo

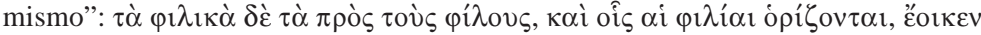

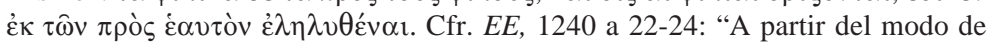
ser en relación con uno mismo han sido definidos los restantes sentimientos de amistad, según los cuales en nuestros discursos solemos examinar": $\alpha$ đò $\delta \dot{\varepsilon}$

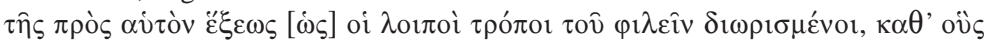

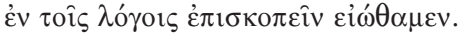

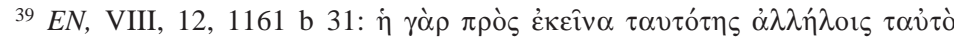
$\pi$ กเฉî.

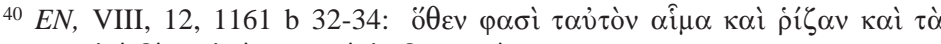

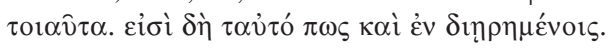


c) amistad consigo mismo

Si consideramos la ética aristotélica como un tratado que se orienta al conocimiento y al estudio del hombre — desde el punto de vista de su comportamiento frente al otro, en la vida social, y frente a sí mismo, en su vida familiar e individual, siendo capaz, en tanto que animal dotado de intelecto, no sólo de adquirir sino también de modificar un determinado carácter y la relación que él guarda con respecto a sus pasiones-, resultará evidente cuán próximo se encuentra su objeto de estudio del de la psicología, por un lado, y, por otro, del de la llamada por Aristóteles ciencia política. Dicha proximidad del objeto de la ética en Aristóteles con relación al campo de la psicología y de la ciencia política, se confirma prácticamente en todos los temas que en sus tratados se abordan como parte del estudio de la ética. El tema de la amistad, por supuesto, no escapa a esta regla. Pues, por una parte, la amistad es considerada, aun antes que la justicia, como el vínculo por excelencia que mantiene unidos a los ciudadanos o miembros de una comunidad política. Por la otra parte, sin embargo, hay que buscar los fundamentos de dicha amistad, de la constitución política y de la justicia, en la vida intrafamiliar y en la relación del hombre consigo mismo. ${ }^{41}$

La cuestión de saber si uno es o no su propio amigo, entraña una dificultad que ante todo conviene resolver. ${ }^{42}$ Toda

${ }^{41}$ EE, VII, 10, 1242 a 40-1242 b: "Por eso en primer lugar en la casa se encuentran los principios y las fuentes de la amistad, de la constitución política y

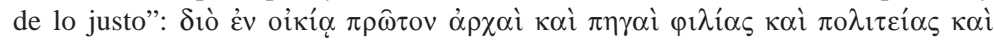

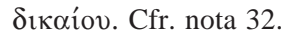

${ }^{42}$ Cfr. $E N$, IX, 4, 1166 a 33: "La cuestión de saber si hay amistad o no en uno

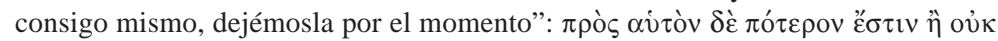

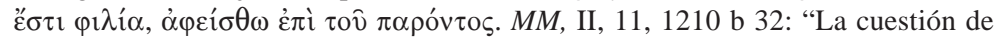
saber si hay amistad en uno consigo mismo dejémosla por ahora, después lo

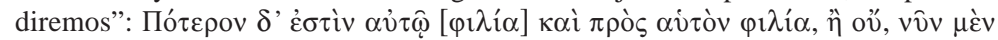

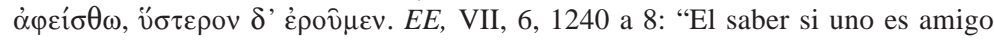


amistad, igual que toda relación de justicia o injusticia, supone la existencia de por lo menos dos sujetos: un amigo se define como aquel que, siendo querido por otro, siente a su vez el mismo afecto por este último, y tal correspondencia no les pasa inadvertida. ${ }^{43}$ Análogamente, aquel que es justo o injusto comete justicia o injusticia en relación con otro; de modo que en toda relación de justicia y amistad se requieren por lo menos dos términos. ¿Cómo se analiza entonces el que se dé en un solo hombre la amistad en relación consigo mismo, si ella supone por lo menos dos partes y un sujeto en tanto que sujeto es uno solo? Tal planteamiento recibe de la teoría de Aristóteles una respuesta que consta de dos partes. La primera se apoya en las diferentes condiciones - cuatro en total— que favorecen una disposición amistosa en el hombre, dándose especialmente en el hombre bueno, y por las cuales se suele definir la amistad; la segunda remite a las partes del alma y a la disposición en la que se encuentra con respecto a ellas el hombre bueno.

Así pues, en primer lugar, algunos consideran al amigo 1) como aquel que anhela y de hecho realiza el bien o lo que parece bien por ningún otro motivo sino por causa del otro; en segundo lugar, consideran al amigo 2) como el que anhela que su amigo exista y viva por causa de él mismo, sentimiento que experimentan las madres con respecto a sus hijos. En tercer lugar, lo definen otros 3) como aquel que pasa los días en compañía y que elige las mismas cosas; o, en cuarto lugar, 4) como aquel que simultáneamente experimenta con el amigo las penas y alegrías, lo cual sucede también especialmente a las madres, por el amor entrañable que sienten por los hijos. ${ }^{44}$

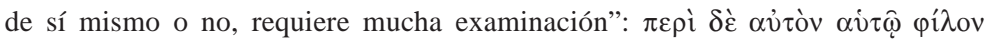

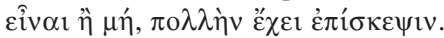

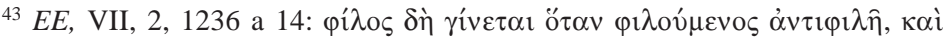

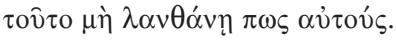

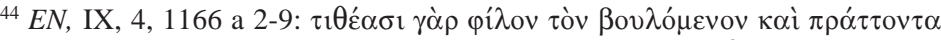

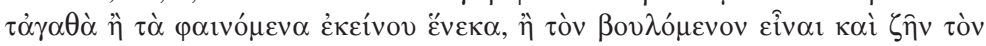


Si bien estas cuatro condiciones se dan sobre todo en el hombre que Aristóteles define como hombre bueno, nada impide que de ellas participen también la mayoría de los hombres, aun cuando éstos fuesen malos, en la medida en que ellos, igual que aquél, sienten agrado en su relación consigo mismos y se consideran hombres buenos.

Es hombre bueno, según Aristóteles, 1) aquel que está de acuerdo consigo mismo, el que apetece las mismas cosas con toda su alma y anhela y practica para sí el bien y lo que parece un bien, y lo hace por causa de sí mismo (pues lo hace teniendo en vista su intelecto y cada uno es su propio intelecto); 2) aquel que anhela vivir y preservarse a sí mismo, especialmente preservar la parte con la que piensa, porque el existir es un bien para él, y la existencia para todo hombre parece consistir en su intelecto o sobre todo en él; 3) tal hombre siente agrado por su propia compañía y anhela pasar el tiempo consigo mismo, pues tanto sus recuerdos del pasado como expectativas acerca del futuro y los objetos de contemplación en el presente son buenos en él y por tanto agradables; 4) aquel, en fin, que comparte sobre todo consigo mismo tanto placeres como dolores y quien siempre disfruta o sufre una misma cosa, no unas veces unas otras veces otras, dado que es, por

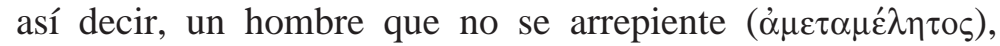
porque no comete nada vergonzoso. ${ }^{45}$

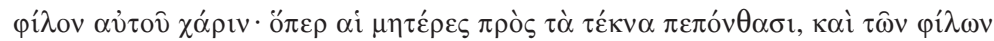

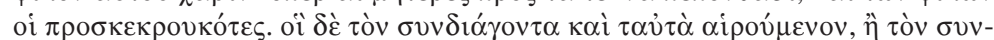

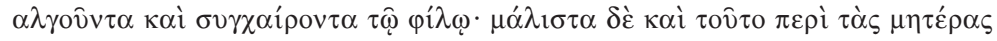

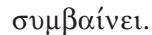

${ }^{45} E N$, IX, 4, 1166 a 13-29: o ôं

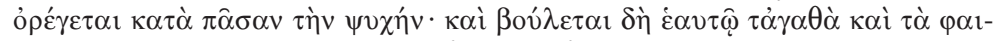

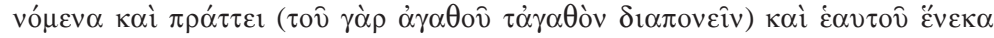

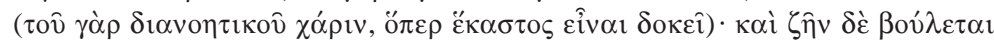

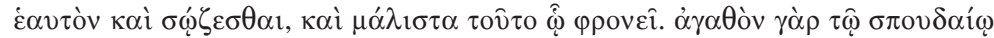

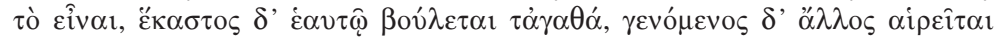

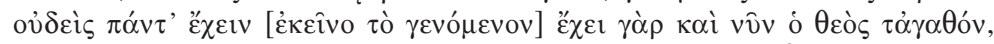

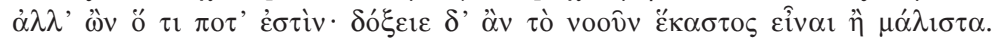

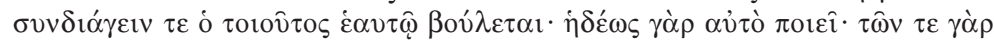


Pues bien, a partir de estas características o condiciones de amistad que se dan en el hombre bueno con respecto a sí mismo, formula Aristóteles en sentido inverso la definición de amistad de uno con respecto al amigo externo: un amigo es otro yo, de modo que, uno se encuentra dispuesto con relación al amigo tal como se encuentra dispuesto con relación a sí mismo. En los Magna Moralia la metáfora del espejo sirve para ilustrar esta relación: pues sólo frente al espejo podemos vernos a nosotros mismos y contemplar en él nuestro rostro, cosa que de otra manera no sería posible; así también en el amigo podemos ver el reflejo de nuestra propia alma; como dice también el proverbio, los amigos son una sola alma. ${ }^{46}$

Pero, ¿cómo se explica pues el hecho de que aquellas condiciones de amistad que primariamente se dan en un hombre, tengan lugar en un solo individuo, si por otro lado se admite que toda amistad o enemistad se da por necesidad entre dos o más individuos, pero no en uno solo? La solución a esta dificultad se encuentra en la explicación del alma del sujeto, en tanto que entidad compuesta de partes. En efecto, si un hombre está de acuerdo consigo mismo, tanto en lo que hace como

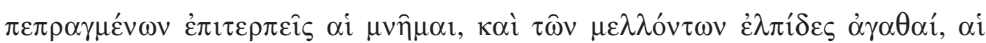

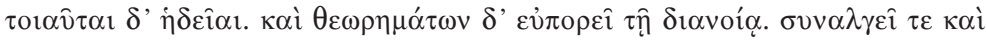

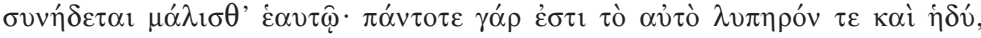

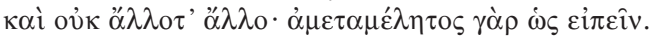

${ }^{46} M M$, II, 15, 1213 a 20-23: "Así pues, tal como cuando queremos ver nuestro rostro, lo vemos mirándonos en el espejo, de manera semejante también si queremos conocernos a nosotros mismos, nos conoceremos viendo a nuestro amigo":

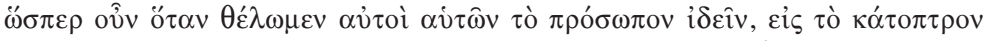

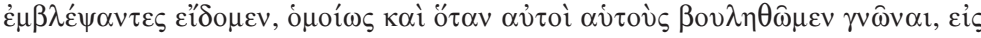

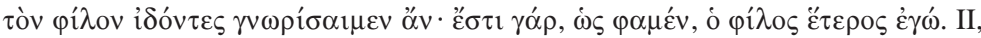
11, 1211 a 32: "Cuando queremos definir a un gran amigo decimos una sola alma, la mía y la de él; así pues, dado que son varias las partes del alma, será una sola alma en el momento en que tanto la razón como las pasiones se encuentren

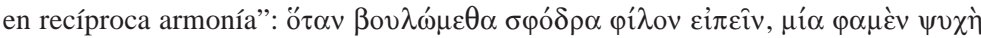

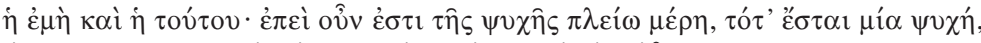

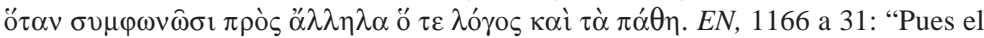

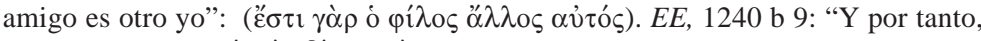

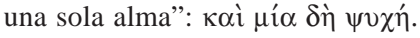


en lo que anhela para sí, es porque las partes de su alma se encuentran en armonía entre sí. Por esta armonía entre las partes de su alma es él constante y congruente entre lo que apetece y lo que hace; él elige lo que es bueno para sí, siendo él semejante a sí mismo y llegando a ser uno solo. ${ }^{47}$ De este modo, el hombre que posee buen carácter, que vive por su intelecto y que no es arrastrado por sus pasiones, es amigo de sí mismo, porque posee dentro de sí aquellas dos partes del alma — la racional y la irracional— que anhelan ser amigas y que es imposible separar. De hecho, aun cuando hubiese discordia entre estas dos partes del alma, como sucede en el caso del incontinente - es decir, de aquél que elige las cosas que le agradan, aun sabiendo que le dañan, en lugar de escoger las que él sabe que son buenas para él, razón por la que parece un hombre dividido, fragmentado en dos o en más partes-, aún en este caso en que el sujeto es enemigo de sí mismo, en la medida en que las partes de su alma parecen desgarrarse entre sí, el individuo permanece siendo uno en tanto que individuo. En este sentido, la amistad hacia uno mismo se parece a la amistad entre parientes por consanguinidad; a los cuales no les es posible disolver ni la una ni la otra. Pues, aun cuando entre ellos surjan diferencias, permanecerán sin embargo siendo parientes consanguíneos, y el individuo seguirá siendo uno, mientras viva. ${ }^{48}$

Por lo anterior resulta evidente que hay hombres en que no se da ninguna de aquellas condiciones por las que se produce la amistad hacia uno mismo. Tal es el caso, por ejemplo, 1) de aquellos que están en conflicto consigo mismos y que no tie-

\footnotetext{
${ }^{47}$ Cfr. EE, VII, 6, 1240 b 19: Pues en medida en que él es en cierto modo semejante a sí mismo, uno solo y de buen carácter, en esa medida es él amigo de

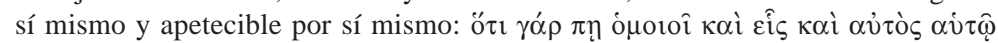

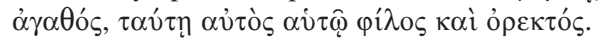

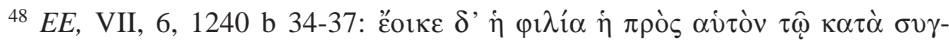

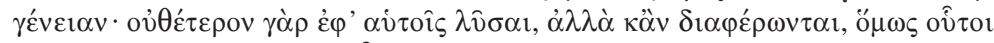

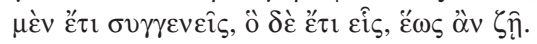


nen en ellos nada amable, de manera que no parecen tener una disposición amistosa ni con relación a sí mismos ni con respecto a otro; ${ }^{49}$ 2) es el caso también de aquellos que por maldad han cometido crímenes, odian y huyen el vivir y cometen suicidio, ${ }^{50}$ 3) o como los incontinentes, quienes, por cobardía e indiferencia se abstienen de realizar aquello que consideran para sí mismos mejor, y eligen, en cambio, las cosas malas arrastrados por el placer; ${ }^{51} 4$ ) es el caso, en fin, de aquellos que buscan la compañía de otros por huir de sí mismos; pues, estando solos recuerdan y esperan muchas cosas desagradables que olvidan si están con otros; así que tampoco pueden alegrarse ni condolerse consigo mismos. Y tan pronto como han disfrutado de un placer sienten arrepentimiento, de modo que su alma es arrastrada de aquí para allá, unas veces sintiendo placer, otras dolor por el reproche, tal como si sus partes intentaran desgarrarla. ${ }^{52}$

Por lo tanto, dado que encontrarse en una disposición de tal naturaleza es una gran desgracia, mientras que, por otra parte, no es posible alcanzar ninguna disposición de amistad si se posee un modo de ser malo, según la teoría de Aristóteles conviene huir con esfuerzo de la maldad e intentar ser bueno. Pues de este modo, uno estaría amistosamente dispuesto hacia sí mismo y también podría llegar a ser amigo de otro. ${ }^{53}$

${ }^{49} E N$, IX, 4, 1166 b 25.

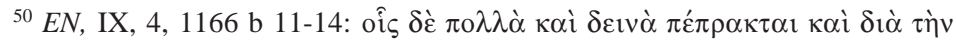

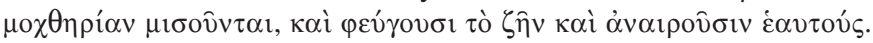

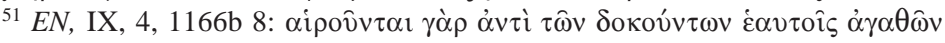

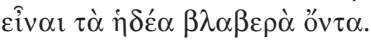

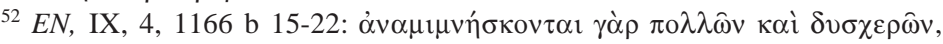

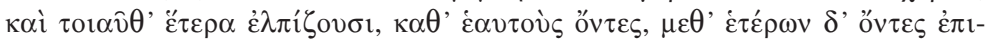

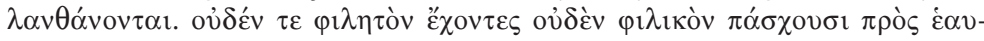

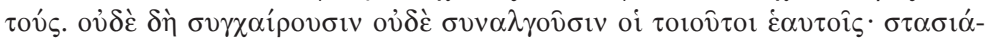

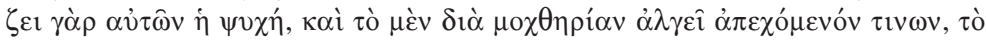

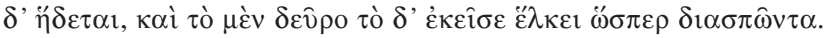

${ }^{53} E N$, IX, 4, 1166 b 27-29:

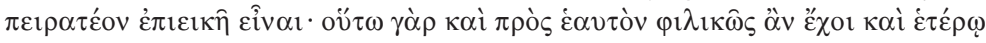

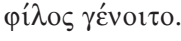


Tras la lectura y análisis de las tesis más importantes que despliega Aristóteles en su tratado de la amistad EN, VIII-IX, podemos establecer preliminarmente: a) que la virtud es el fundamento sobre el cual Aristóteles estructura su teoría de la amistad en su conjunto; b) que la amistad que se funda en la virtud supone la posesión y actualidad de las virtudes éticas, y sólo por semejanza con ella las demás clases - la amistad por placer y la amistad por utilidad - son consideradas especies de amistad; c) que la amistad de uno en relación consigo mismo es idéntica de la que se da en un hombre de buen carácter, $\sigma \pi \mathrm{ov \delta \alpha î}$, o sólo puede darse en un hombre de carácter excelente; d) que el sentimiento de afecto hacia uno mismo es fuente y principio del sentimiento de afecto y de amistad hacia los demás, de manera que la amistad con respecto a los demás depende y procede de la amistad de uno en relación consigo mismo. De estas tesis se desprende que no es posible la amistad hacia el prójimo sin la virtud y sin la existencia previa de la amistad de uno hacia uno mismo; de modo que, si uno quisiera establecer una relación de amistad con alguien más, tendría que establecer, en primer lugar, una relación de amistad consigo mismo, lo cual no es posible sin la adquisición previa de las demás virtudes éticas.

El tratado de la amistad parece estar situado en la cúspide de la doctrina ética de Aristóteles y, según la disposición interna de la $E N$, estar estructurado de tal modo que hace las veces de eslabón entre los libros anteriores I-(VI)-VII y el libro X, dedicado en gran parte a la tesis sobre la anterioridad de la vida contemplativa respecto de la vida política. Los libros VIII y IX parecen constituir, por un lado, una especie de síntesis —en la que, a través de la teoría de la amistad, se resume y expone la disposición ética, $\varphi \imath \lambda i ́ \alpha$, que en sí misma estructura y reúne de una sola vez todas las virtudes del carácter previamente analizadas-, y, por otro, una especie de puente hacia el tratado sobre la vida contemplativa. En el centro del tratado de la amistad, a su vez, como punto culmi- 
nante y decisivo sobresale la $\varphi \imath \lambda \alpha v \tau i ́ \alpha$. A lo largo de la exposición aristotélica de la amistad parecería que subyace como tesis fundamental la postulación de que la amistad de uno consigo mismo, la $\varphi \imath \lambda \alpha v \tau i ́ \alpha=$ la amistad que se funda en la virtud, es no sólo la causa y conditio sine qua non de que pueda darse la amistad con nuestros semejantes: padres, hermanos, hijos, parientes, seres queridos, vecinos o ciudadanos, sino también la condición para pasar de la vida activa a la vida contemplativa. ${ }^{54}$

\footnotetext{
${ }^{54}$ Varios pasajes muestran, en el curso de la disquisición acerca de la $\varphi \imath \lambda \alpha v$ -

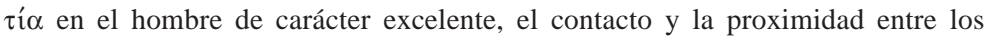
tratados de la amistad y la contemplación. Cfr. EN, IX, 91170 a 25-1170 b 21; IX, 4, 1166 a 18; IX, 8, 1169 a 2-3; X, 7, 1178 a 2.
} 